\title{
Microwave irradiation of human brain tissue: production of microscopic slides within one day
}

\author{
M E BOON,* E MARANI, $\dagger$ P J M ADRIOLO,* J W STEFFELAAR, $\ddagger$ G Th A M BOTS, $\uparrow$ \\ L P KOK§ From the * Leiden Cytology and Pathology Laboratory, Leiden, the + Laboratory for Anatomy \\ and Embryology, University of Leiden, the $\ddagger$ Department of Surgical Pathology, Municipal Hospitals of The \\ Hague, the \Department of Pathology, University Hospital Leiden, and the §Institute for Theoretical Physics, \\ University of Groningen, The Netherlands
}

SUMMARY A three step method using microwave irradiation enabled microscopic slides of human brain tissue to be obtained within one working day: steps 1 and 2 hardened and solidified brain tissue; step 3 completed formalin fixation. The efficacy and precision of the method was compared with slides of conventionally processed brain tissue that had been fixed in formalin for six weeks. The microscopic quality of the sections was excellent with good presentation of brain tissue and equalled that of conventionally processed slides.

In many pathology laboratories brains removed at necropsy are suspended in $10 \%$ buffered formalin and fixed for at least six weeks. Unfixed brain tissue is soft and delicate, requiring careful handling. The cerebrum is therefore only cut after fixation. ${ }^{1}$ To shorten fixation time (from six to three weeks) perfusion with formalin is sometimes carried out. ${ }^{2}$ If, due to time pressure, the brain has to be sectioned before it can be hardened by the fixative, very thick slices must be cut with great care. Even then distortion can hardly be avoided. The thick slices can be fixed in $\mathbf{4 8}$ hours provided that the fixative is changed several times. ${ }^{1}$

Since the early 70 s, it has been reported that heat produced in tissues by microwave irradiation can be used for fixation..$^{3-5}$ This principle is used in neurochemical and pharmacological research in laboratory animals. ${ }^{67}$ Reported fixation times are in the range of seconds to minutes. Microwave irradiation can be of value in the hardening procedure to permit cutting ${ }^{8}$ and in the fixation step..$^{9}$ Moreover, in tissue treated in this way the fixative diffuses more rapidly. ${ }^{10}$

In this paper we report how this three step action of microwave irradiation can be exploited for use on human brain tissue.

\section{Material and methods}

Fresh human brains from four patients without major cerebral disease, obtained within 12 to 18 hours after death, were used for this study. There were two men

Accepted for publication 16 December 1987 and two women ranging in age from 26 to 82 years Causes of death were cardiac infarct $(n=3)$ and acute lymphatic leukaemia $(n=1)$.

Two types of microwave ovens were used: the domestic Miele oven M696 and the prototype microwave oven, designed especially for use in pathology laboratories (Model H2500; Polaron, Watford, UK). Maximum temperature and power level can be set in these ovens. The temperature was programmed for $50^{\circ} \mathrm{C}$. The temperature probe was placed $1-2 \mathrm{~cm}$ below the surface of the tissue, or in the jar containing formalin. The power setting was $25 \%$ (indicated as 150 $\mathrm{W}$ on the display of the Miele oven).

\section{MICROWAVE TECHNIQUE}

The brains were cut into a right and left half. One half brain was used for the microwave method and the other half was processed as usual-suspended in formalin and fixed for six weeks.

The microwave method was established according to our experience with microwave fixation of brain tissue." 12 The method comprises two hardening steps (microwave steps 1 and 2), and two fixation steps (one soaking step, and microwave step 3). One half brain is sprinkled with physiological saline, put in a plastic bag to prevent dehydration, and placed in the microwave oven.

Step 1 The specimen is microwaved for 30 minutes.

The specimen is cut in $1 \mathrm{~cm}$ thick slices.

The slices selected for further investigation are put on the bottom plate of the oven sprinkled with physiological saline and covered by plastic. 
Step 2 The slices receive microwave irradiation for 15 minutes.

Blocks of $2 \times 2 \times 0.5 \mathrm{~cm}$ are cut for further microscopic investigation.

The blocks are immersed in $10 \%$ formalin and soaked at room temperature in the fixative for three and a half hours. This is done in plastic jars containing $40 \mathrm{ml}$ fixative.

Step 3 The plastic jar with contents (lid removed) receives microwave treatment for six minutes.

The blocks are completely fixed and ready for histoprocessing.

The other half brain is fixed in $10 \%$ formalin for six weeks. Blocks from the same areas as above are removed for further microscopic investigation.

To obtain paraffin sections blocks were processed in a Shandon tissue processor 2L (Shandon, UK), or in the microwave oven. ${ }^{1314}$ Freeze sectioning was also performed.

\section{STAINING}

The paraffin sections were stained with haematoxylin and eosin, Nissl, Klüver-Barrera, and Bodian methods. The peroxidase technique was also applied for colouring neurofilament using a monoclonal antibody." 12 Neurofilament antibody, which recognises low (70 kD), medium (150 kD), and high (200 kD) neurofilament subunits, was made in our laboratory. Neurofilament ascites was diluted 1/2500 and incubated overnight. The second antibody goatanti-mouse serum $(1 / 50)$ (CLB) was carried out for two hours at room temperature followed by the PAP technique (NORDIC), diluted $1 / 300$ for one hour at room temperature. The incubation medium contained $0.003 \% \mathrm{H}_{2} \mathrm{O}_{2}$ and $0.04 \%$ diaminobenzidine. Controls contained normal mouse serum or SP(2)O fluid, with the second antibody step omitted.

\section{Results}

After the first microwave step the outer zone of the half brain was sufficiently hardened to permit sectioning. In these slices the solidified zone was $2-2.5 \mathrm{~cm}$. The deeper brain tissue was still more or less soft. The solidified zone was greyish-white, differing from the pink-white soft brain tissue. After the second microwave step the slices were completely greyish-white and consolidated throughout. At the end of the third microwave step (blocks in formalin) the tissue was completely grey.

The microscopic quality of the sections was excellent. The colour balance in the haematoxylin and eosin sections was pleasant, with a slightly more pronounced eosinophilia than in the control slides. Colouration times in microwaved and non-microwaved tissue were the same. The erythrocytes were intact: in case 1 extravasation of the erythrocytes could therefore be well observed. Neuropils and neurons were visible, and the nuclear details in the cerebellar granular cells and Purkinje cells were good.

With Bodian staining the fibres could be clearly discerned and in strongly myelinated tracts the axon

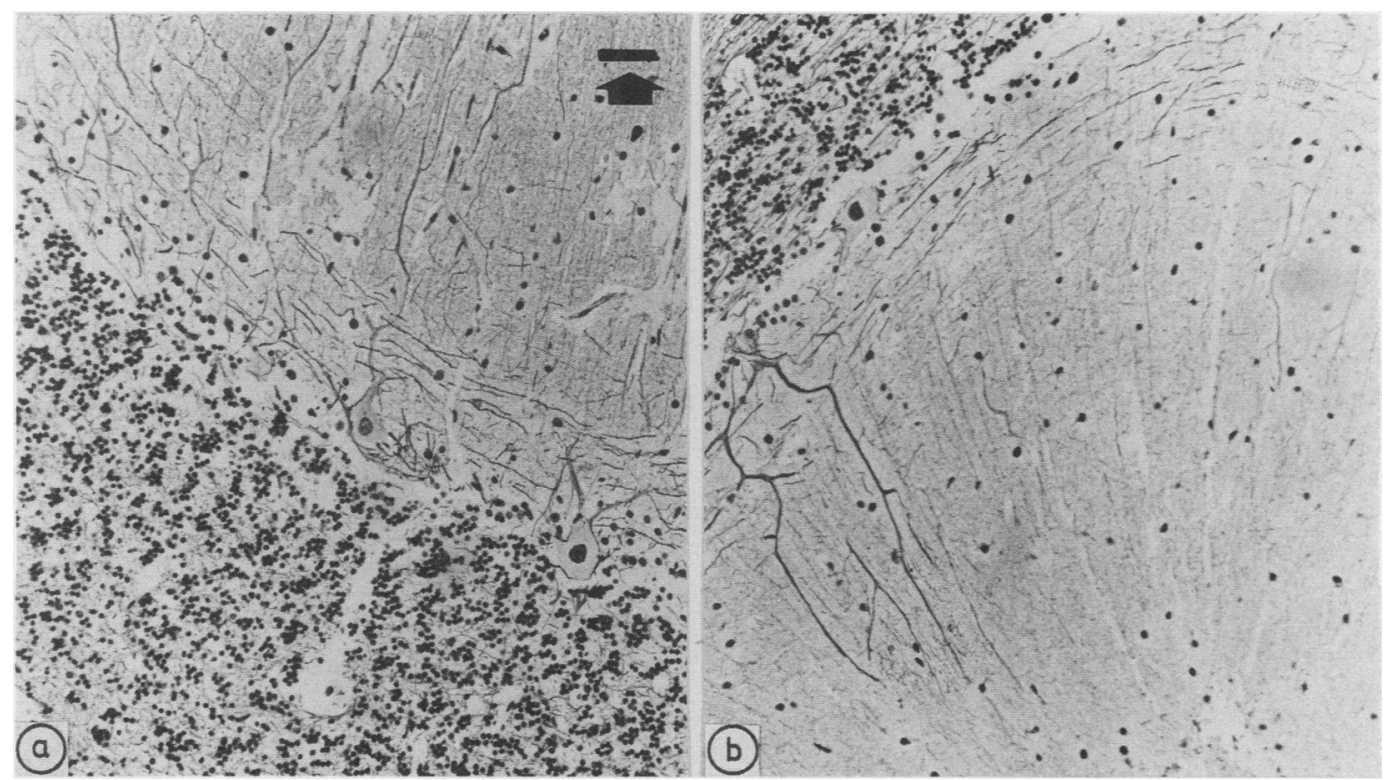

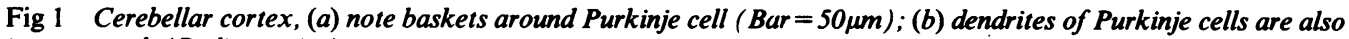
impregnated. (Bodian stain.) 
core was positive, leaving the myelin sheath unstained (figs la and b). There were no differences between staining qualities in the microwave and the control sections.

With neurofilament monoclonal antibody staining the fibres in the tracts were brown (fig 2). The baskets around the Purkinje cells were clearly positive (fig 2 ). The Purkinje cells were, as anticipated, negative.

The Klüver-Barrera staining gave excellent results compared with that of control sections (fig 3).

Patterns with Nissl staining were identical with tho' $\mathrm{e}$ in the control slides, showing the Nissl substance in strong contrast.

\section{Discussion}

With microwave irradiation, the time required for fixation and histoprocessing of whole human brains can be shortened from 43 days to a working day (table), without compromising the microscopic quality. All staining methods used closely resembled results obtained in conventionally obtained slides.

The water in the brain tissue absorbs microwave energy and this ensures that the amplitude (intensity) of the waves is diminished on penetration: energy deposition therefore becomes less intensive. The greater the absorption, the more superficial the penetration of the microwaves. ${ }^{1314}$ Penetration depth of microwaves varies between the tissues processed in the pathology laboratory. ${ }^{15}$ From the dielectric data derived from the biological material of Foster and

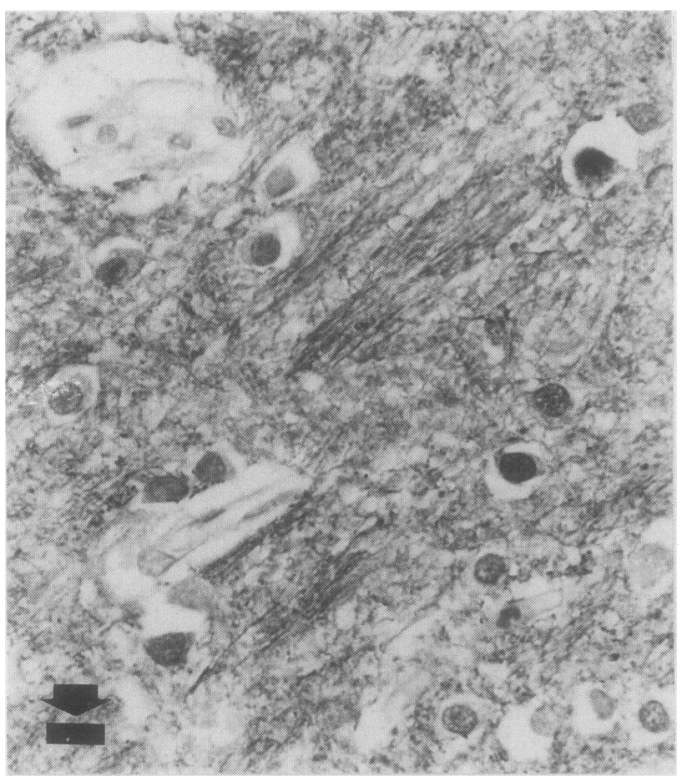

Fig 2 Neurofilament monoclonal antibody distribution in human striatum. (Bar $=25 \mu \mathrm{m}$.)

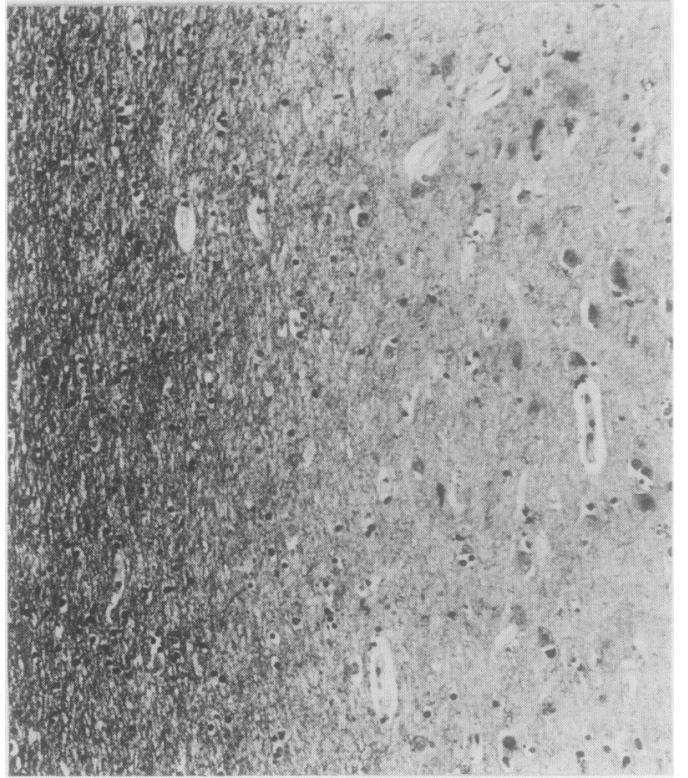

Fig 3 Klüver-Barrera stain of cerebral cortex. Note good visibility of fibre layer and cortical cells.

Schwan ${ }^{16}$ we calculated that the penetration depth for brain at $2.45 \mathrm{GHz}$ is larger than that for muscle and skin, which in turn is larger than that for water. In fact, it is greater than $2 \mathrm{~cm}$. In the second hardening step, the slices are $1-1.5 \mathrm{~cm}$ thick, and hence microwaves penetrate throughout, permitting complete consolidation. The temperature increase results in a change in brain proteins, ${ }^{9}$ visible by the change in colour and hardening of the brain tissue. The macroscopic structures in the brain are clearly visible in these microwaved brain slices, and these can be photographed with good results. The slices can be wrapped in sterilised plastic bags (microwave irradiation sterilises) and kept in the refrigerator for one week. The decision must then be made as to which slices to store in fixative and which to dispose of.

After three and a half hours in formalin the selected tissue blocks are completely impregnated, or more

Table Time required to obtain stained sections from removed brain

\begin{tabular}{ll}
\hline Method & Time (days) \\
\hline $\begin{array}{l}\text { Conventional method with fixation before } \\
\text { cutting }\end{array}$ & 43 \\
$\begin{array}{l}\text { Conventional method without fixation before } \\
\text { cutting }\end{array}$ & 3 \\
$\begin{array}{l}\text { Microwave method with microwave } \\
\text { histoprocessing }\end{array}$ & 5 hours \\
$\begin{array}{l}\text { Microwave method with freeze sectioning } \\
\text { Microwave method with automated tissue } \\
\text { processing }\end{array}$ & 4 hours \\
\hline
\end{tabular}


Fast microwaving of human brains

precisely formulated with its hydrated product methylene glycol. Microwave irradiation results in a rapid conversion of the inactive methylene glycol (present throughout the tissue) into the active formalin. The formalin is swiftly bound to the tissue proteins. ${ }^{1017}$ At room temperature, these procedures require a long period of time. ${ }^{17}$ Our experiments showed that five minutes of microwave treatment of the formalin soaked tissue gives optimal fixation. Longer irradiation is not harmful but does not improve the microscopic results. Undesired erythrolysis, found in microwaved tissue ${ }^{9}$ does not occur when followed by formalin fixation. ${ }^{10}$

The sections cut from the blocks processed in the autoprocessor (containing two formalin baths) closely resembled the control slides. We consider that the two formalin steps of the autoprocessor are unnecessary when our method is used. Eliminating the formalin steps of histoprocessing means reductions in time and cost. When the blocks are processed in the microwave oven no formalin bath is needed. ${ }^{14}$

Leong and Duncis ${ }^{8}$ described the use of microwave irradiation for the rapid fixation of large biopsy specimens. They used this method for gastric specimens, segments of small and large bowel, mastectomy specimens, gall bladders, lobes of liver, lobes of thyroid, lobes of lung uteri, but not for brain tissue. With their method the formalin steps were completely omitted. In our experience, the microscopic results without formalin can be slightly different from those with formalin. ${ }^{11} 1218$ As we wanted to achieve patterns normally produced by formalin or fast formalin fixation, ${ }^{19}{ }^{20}$ by conventional and microwave methods, we included formalin fixation in our procedure. Contact with material impregnated with formalin, however is highly unpleasant because of its penetrative odour. Many pathologists and laboratory technicians have acquired a serious form of formalin allergy. Therefore our goal was to devise a method in which the brain tissue sliced by the pathologist does not contain formalin. Trimming the blocks to the required size was done on material which had not been in contact with formalin. This goal was achieved by hardening the tissue first in a two step microwave procedure using saline.

Because the method of solidifying brain tissue permits rapid cutting, the inside of the brain can be seen the day the necropsy is performed.

\section{References}

1 Bancroft JD, Stevens A. Theory and practice of histological techniques. 2nd ed. Edinburgh: Churchill Livingstone, 1982.

2 Beach TG, Tago H, Nagai T, Kimura H, McGeer PL, McGeer EG. Perfusion-fixation of the human brain for immuno histochemistry: Comparison with immersion-fixation. $J$ Neurosci Methods 1987;19:183-92.

3 Mayers CP. Histological fixation by microwave heating. J Clin Pathol 1979;23:273-6.

4 Bernard GR. Microwave fixation as a generator of heat for histological fixation. Stain Technol 1974;49:215-24.

5 Gordon HW, Daniel EJ. Preliminary report: microwave fixation of human tissues. Am J Med Technol 1974;40:441-2.

6 Ogasahara S, Taguchi Y, Wada H. Changes in the levels of cyclic nucleotides in rat brain during the sleep-wakefulness cycle. Brain Res 1981;213:163-71.

7 Blank CL, Stavinoha WB, Maruyama Y, eds. Symposium of the 8th international congress of pharmacology on drug effects on rapidly metabolized compounds in the CNS: rapid tissue fixation with microwave irradiation. Advances in the Biosciences. Vol 45. Microwave fixation of labile metabolites. New York: Pergamon Press, 1983:107-9.

8 Leong ASY, Duncis CG. A method of rapid fixation of large biopsy specimens using microwave irradiation. Pathology 1986;18:222-5.

9 Hopwood D, Coghill G, Ramsey J, Milne G, Keer M. Microwave fixation: its potential for routine techniques, histochemistry, immunochemistry, and electron microscopy. Histochem $J$ 1984;16:1171-92.

10 Boon ME, Gerrits PO, Moorlag HE, Nieuwenhuis P, Kok LP. Formaldehyde fixation and microwave irradiation. Histochem $J$ (in press).

11 Marani E, Boon ME, Adriolo PJM, Rietveld WJ, Kok LP. Microwave-cryostat technique for neuroanatomical studies. J Neurosci Methods 1987;97-101.

12 Marani E, Guldemond JM, Adriolo PJM, Boon ME, Kok LP. The microwave Rio-Hortega technique: a 24 hours' method. Histochem $J$ (in press).

13 Kok LP, Boon ME, Ouwerkerk-Noordam E, Gerrits PO. The application of a microwave technique for the preparation of cell blocks from sputum. J Microscopy 1986;144:193-9.

14 Boon ME, Kok LP. Microwave cookbook of pathology: the art of microscopic visualization. Leiden: Coulomb Press, Leiden, 1987:28-54.

15 Kok LP. Fundamentals of microwave-stimulated staining. In: Boon ME, Kok LP, eds. Standardization and quantitation of diagnostic staining in cytology. Leiden: Coulomb Press Leiden, 1986:82-97, 125-9, 158-9.

16 Foster KR, Schwan HP. Dielectric properties of tissues-a review. In: Polk C, Postow E, eds. Handbook of biological effects of electromagnetic radiation. New York: CRC Press, 1986:101-9.

17 Fox CH, Johnson FB, Whiting J. Roller PP. Formaldehyde fixation. J Histochem Cytochem 1985;33:845-53.

18 Kok LP, Boon ME, Suurmeyer AJH. Major improvement in microscopical-image quality of cryostat sections: Combining freezing and microwave-stimulated fixation. Am J Clin Pathol 1987;88:620-3.

19 Login GR. Microwave fixation versus formalin fixation of surgical and autopsy tissue. Am J Med Technol 1978;44:435-7.

20 Zimmerman GR, Raney JA. Fast fixation of surgical pathology specimens. Lab Med 1972;3:29-30.

Requests for reprints to: Dr Mathilde E Boon, Leiden Cytology and Pathology Laboratory, P.O. Box 16084, 2301 GB Leiden, The Netherlands. 